Trab. Ling. Aplic., Campinas, 45(2): 225-238, Jul./Dez. 2006

\title{
A RETEXTUALIZAÇÃO DOS CONCEITOS DE LETRAMENTO, TEXTO, DISCURSO E GÊNEROS DO DISCURSO NOS PCN DE LÍNGUA PORTUGUESA
}

\author{
SIMONEBUENOBORGES DA SILVA ${ }^{1}$ \\ Doutoranda - UNICAMP
}

\begin{abstract}
RESUMO
Tomaremos para análise, neste artigo, a definição dos conceitos de letramento, texto, discurso, gêneros do discurso apresentados nos Parâmetros Curriculares Nacionais (PCN) de Língua Portuguesa para o primeiro e segundo ciclos do Ensino Fundamental. Trata-se de um documento divulgado pelo Governo Federal em 1997 que visa a parametrizar o ensino nas séries iniciais. Nele, vários conceitos da esfera acadêmica são utilizados como subsídio que deve embasar as diretrizes para o ensino de Língua Portuguesa. Com o objetivo de observar como os conceitos supracitados elaborados e discutidos na esfera acadêmica 'migram' para a esfera educacional, nós os analisaremos à luz do conceito de retextualização. Assim, este artigo traz uma análise comparativa das definições apresentadas em textos fontes e suas formas retextualizadas nos PCN para discutir a legibilidade do documento parametrizador, levando em conta seu público alvo principal, qual seja: o professor do primeiro e segundo ciclos do Ensino Fundamental.
\end{abstract}

Palavras-chaves: professores; retextualização; conceitos.

\section{ABSTRACT}

In this article, we analyse the definitions of literacy, text, discourse and genre of discourse presented in the document National Curriculum Guidelines - Portuguese Language, published by the Brazilian Ministry of Education in 1997 for the first and second cycles of Primary Education. One of the main objectives of the document is to offer guidelines to organize education at this level and help teachers to change their practice. Our aim is to analyse how academic concepts are transferred to the educational sphere. The article compares the definitions as presented in academic texts with the retextualized forms presented in the official document in order to discuss its legibility taking into consideration its main audience, that is, the teacher at the fundamental level.

Key-words: teachers; retextualization; concepts.

\section{INTRODUÇÃO}

O objetivo do trabalho que ora se apresenta é analisar alguns conceitos lingüísticos nos PCN de Língua Portuguesa para o primeiro e segundo ciclos do ensino fundamental (doravante PCN) para compreender como os conceitos elaborados e discutidos na esfera acadêmica vêm sendo abordados, compreendidos e utilizados na esfera educacional. Com

\footnotetext{
1 Agradeço o apoio da FAPESP.
} 
SILVA - A retextualização dos conceitos de letramento...

base no conceito de retextualização, analisaremos a formulação retextualizada dos conceitos de letramento, texto, discurso e gêneros do discurso apresentada nos PCN comparando-as com os textos que os conceituam na esfera acadêmica e que serviram de referência para a retextualização do documento. A seleção desses conceitos justifica-se por sua relevância no documento parametrizador, ou seja, tratam-se de conceitos que fundamentam os parâmetros curriculares e que, portanto, são 'conceitos-chave' para a compreensão da perspectiva de ensino abordada na proposta.

Para desenvolver a análise, utilizaremos a metodologia, baseada em Marcuschi (2001), de comparação entre a forma textual dos conceitos na origem (texto fonte) e a forma retextualizada nos PCN (texto alvo). A comparação entre os textos nos permitirá compreender os tipos de operações realizadas no processo de retextualização em foco. Este estudo não pretende propor uma definição dos conceitos analisados, mas visa a observar os mecanismos utilizados no processo de reformulação dos conceitos para um público não especialista em lingüística. As formas retextualizadas dos conceitos de letramento, texto, discurso e gêneros do discurso nos PCN visariam, em princípio, a facilitar sua compreensão para os professores do ensino fundamental de todos o país.

\section{A RETEXTUALIZAÇÃO DA ESCRITA PARA A ESCRITA}

O conceito de retextualização foi proposto por Travaglia (1992) ao estudar o processo de tradução via textualidade. A autora entende que a tradução "é a passagem de um texto original regido numa língua de partida para um texto regido numa língua de chegada" (p.112). Deste modo, a mudança da língua em que o texto foi escrito implica necessariamente em uma mudança na textualidade. Retextualizar é, na perspectiva da tradução, transformar um todo comunicativo expressivo escrito, em outro escrito, em virtude de uma necessidade imposta pela alteração da língua.

Marcuschi (2001) retoma o conceito de retextualização deslocando-o da tradução para o campo da Lingüística, ao estudar as transformações que um texto oral sofre ao ser transposto para a escrita. Apesar de sua pesquisa enfocar o processo de retextualização da fala para a escrita, o autor aponta quatro possibilidades de retextualização, quais sejam: 1 . d a fala para a fala; 2 . da fala para a escrita; 3 . da escrita para a fala e, 4 . da escrita para a escrita.

A retextualização é, então, um processo de transformação de um texto em outro, em virtude da alteração de algum elemento que o compõe: a língua, no caso da tradução, a modalidade, no caso da fala para a escrita e vice-versa ou o próprio gênero do texto, no caso da retextualização da escrita para outra escrita. Nesta última possibilidade está o foco de nossa análise. Na retextualização, algumas formas lingüísticas podem ser eliminadas ou incluídas, substituídas ou reordenadas. São alterações motivadas por uma série de fatores que envolvem a produção do novo texto (objetivo, público alvo, código, língua, gênero etc.). Quando há uma alteração no gênero do texto ocorrem, também, algumas outras alterações lingüísticas (lexical, textual, sintático-estrutural etc.) peculiares ao novo gênero. 
Na perspectiva de nosso trabalho, a principal variável relaciona-se à finalidade do texto. Essa variável fornecerá os parâmetros para o processo de retextualização do texto escrito no domínio discursivo acadêmico para o domínio discursivo oficial ao qual pertence o documento curricular.

Matencio (2002) defende que a retextualização, entendida como produção de um novo texto a partir de um ou mais textos-base, pressupõe, necessariamente, uma mudança nos propósitos, na finalidade, porque, se não o fosse, teríamos um processo de reescrita de um mesmo texto em que o quadro de referência não se altera. No processo de retextualização "o sujeito trabalha sobre as estratégias lingüísticas, textuais e discursivas identificadas no texto base para, então, projetá-las tendo em vista uma nova situação de interação, portanto, um novo enquadre e um novo quadro de referência".

Quanto aos PCN, há uma retextualização de textos do domínio discursivo acadêmico em virtude da nova situação comunicativa em que os conceitos figuram: os interlocutores são outros e os objetivos também o são. O diálogo entre os pares acadêmicos é substituído pelo diálogo (ou uma tentativa de) entre o Estado e seus subordinados, ou seja, muda-se o objetivo e o público alvo, enfim muda-se toda a situação socio-comunicativa. Os conceitos elaborados e discutidos na instância acadêmica passam, nos PCN, a ter finalidade de redefinir ou parametrizar os conteúdos a serem trabalhados no ensino fundamental, em âmbito nacional. Nos PCN, os conceitos determinam o recorte através do qual os conteúdos curriculares devem ser compreendidos e ensinados.

Para desenvolver nossa análise, utilizaremos a metodologia proposta por Marcuschi (op.cit.) que consiste na comparação entre os textos fonte (origem) e alvo (forma retextualizada). No processo de retextualização da fala para a escrita o autor observou nove operações subdividas em dois blocos, sendo um o das operações de regularização e idealização e outro o das operações de transformação. As do primeiro bloco $\left(\right.$ da $1^{\mathrm{a}}$ a $\left.4^{\mathrm{a}}\right)$, estão mais relacionadas a transcodificação e editoração ${ }^{2}$, ou seja, voltam-se mais para passagem do material sonoro para o escrito. As demais (da $5^{\mathrm{a}}$ a $9^{a}$ ) trazem alterações de natureza sintática, semântica, pragmática e cognitiva.

A retextualização da escrita para a escrita não segue as nove operações descritas por Marcuschi, já que algumas delas são específicas do processo de transposição do material sonoro para as normas da escrita. Em nosso trabalho pudemos verificar procedimentos diferentes dos apontados por Marcuschi, os quais apresentamos no quadro abaixo:

2 Marcuschi (op. cit.: 49 a 62) define transcodificação como "a passagem da oralidade para a escrita levando-se em conta apenas as normas de transcrição". Já a editoração "é um processo de idealização dos dados com o objetivo de torná-los gramaticais e analisáveis" (p.55). Nem a transcodificação, nem a editoração são, propriamente, casos de retextualização. 
SILVA - A retextualização dos conceitos de letramento...

\begin{tabular}{|c|c|}
\hline OPERAGCOES & NIVEL DE TRANSFORMACẼ̃O \\
\hline I - eliminação lexical & Uma operação estilística de supressão de palavras. \\
\hline II - substituição lexical & $\begin{array}{l}\text { Operação de adequação ao novo texto. Leva em } \\
\text { conta os novos interlocutores e os ajustes necessários } \\
\text { à textualidade. }\end{array}$ \\
\hline III - substituição sintática & $\begin{array}{l}\text { Operação de ajuste/adequação ao novo texto. Leva } \\
\text { em conta principalmente a construção composicional } \\
\text { do gênero do texto alvo. }\end{array}$ \\
\hline $\begin{array}{l}\text { IV - eliminação de itens } \\
\text { informacionais }\end{array}$ & $\begin{array}{l}\text { Operação relacionada diretamente com o nível } \\
\text { semântico. Ocorre uma seleção das informaçōes a } \\
\text { serem eliminadas/omitidas. }\end{array}$ \\
\hline V - reordenação tópica & $\begin{array}{l}\text { Operação argumentativa em que é alterada a ordem } \\
\text { dos argumentos. }\end{array}$ \\
\hline
\end{tabular}

A eliminação lexical (I) é uma operação estilística de supressão de palavras, sem que ocorra a eliminação de itens informacionais que, para nós, consiste em um outro mecanismo de retextualização. A eliminação de itens informacionais (IV) aproxima-se do resumo, pois há uma seleção do que será informado e do que será omitido. As substituições lexicais (II) e sintáticas (III) operam no nível do estilo-gênero, ou seja, são alterações que acontecem para a adequação do texto ao gênero pretendido. Estas substituições também interferem no nível argumentativo do novo texto. Por fim, a reordenação tópica (V) que incide na ordenação e hierarquização argumentativa do novo texto.

\section{O SIGNIFICADO DE LETRAMENTO NOS PCN}

O termo letramento aparece escrito, pela primeira vez, nos PCN, na página vinte e três e é abordado como sendo um conceito que compõe o rol de conhecimentos prévios do leitor, tendo sua definição apresentada em nota. No entanto, a compreensão desse conceito é fundamental para o entendimento do texto, ou seja, letramento é um conceito-chave, porque, segundo a proposta, se relaciona ao papel que a escola deve desempenhar no ensino dos usos sociais da escrita. Observemos, então, o parágrafo em que o conceito é mencionado:

Essa responsabilidade é tanto maior quanto menor for o grau de letramento das comunidades em que vivem os alunos (PCN - vol.2: 23)

O conceito de letramento, no texto, faz referência à responsabilidade da escola em garantir o acesso aos saberes lingüísticos. Entretanto, sua definição é apresentada apenas na nota cinco que, por sua vez, remete a outros conceitos específicos da área dos estudos da linguagem como práticas discursivas e graus de letramento que também precisariam de uma explicação, uma vez que mencionados a um público não lingüista. A definição é fruto da retextualização de fragmentos de um texto de Kleiman (1995: 18-19). O quadro abaixo apresenta o texto dos PCN (texto alvo) ladeado pelo texto de Kleiman (texto fonte). 
Para efeito de análise, segmentamos o texto em porções menores com o propósito de melhor visualizar a relação entre a fonte e o alvo.

\begin{tabular}{|c|c|c|}
\hline ENUNCIADOS & TEXTO FONTE & PCN - TEXTO ALVO \\
\hline 1 & $\begin{array}{l}\text { Podemos definir hoje o letramento } \\
\text { como um conjunto de práticas }\end{array}$ & $\begin{array}{l}\text { Letramento, aqui, é entendido como o } \\
\text { produto da participação em } \\
\text { pra'ticas sociais }\end{array}$ \\
\hline 2 & $\begin{array}{l}\text { que usam a escrita, enquanto } \\
\text { sis tema simbólico e enquanto } \\
\text { tecnologia, em contextos específicos, } \\
\text { para objetivos específicos (p. 19) }\end{array}$ & $\begin{array}{l}\text { que usam a escrita como sis tema } \\
\text { simbólico e tecnologia }\end{array}$ \\
\hline 3 & $\begin{array}{l}\text { o letramento significa uma prática } \\
\text { discursiva de determinado grupo } \\
\text { social, }\end{array}$ & São práticas discursivas \\
\hline 4 & $\begin{array}{l}\text { que está relacionada ao papel da } \\
\text { escrita para tornar significativa } \\
\text { essa interação oral, }\end{array}$ & $\begin{array}{l}\text { que precisam da escrita pra torná- } \\
\text { las significativas }\end{array}$ \\
\hline 5 & $\begin{array}{l}\text { mas que não envolve, } \\
\text { necessariamente, as atividades } \\
\text { específicas de ler e escrever. (p. } \\
\text { 18) }\end{array}$ & $\begin{array}{l}\text { ainda que às vezes não envolvam } \\
\text { as atividades específicas de ler e } \\
\text { excrever. }\end{array}$ \\
\hline
\end{tabular}

Na seqüência apresentada, é possível observar operações estilísticas de: a) substituição lexical (II operação) em que a conjunção enquanto é substituída por como b) eliminação (operação I) da segunda ocorrência da conjunção enquanto

c) substituição de todo um segmento que envolve as operações II e III: Um conjunto de práticas por o produto da participação em práticas sociais.

Entretanto, a retextualização do primeiro enunciado não pode ser vista como uma reprodução do conceito no texto fonte, já que um lugar enunciativo diferente é instaurado - "Letramento aqui", e com isso, expressiva mudança conceitual começa a ser feita. Definir letramento como um conjunto de práticas não equivale a dizer o produto da participação, pois produto (aquilo que resulta de qualquer processo ou atividade) está mais diretamente ligado a resultado, e conjunto (reunião das partes que formam um todo) ${ }^{3}$ traz a idéia de totalidade. Num evento de letramento, o produto poderia ser uma série de textos (tanto orais quanto escritos) e atitudes, já o letramento refere-se a própria prática em si. Conceituar letramento como sendo um produto não corresponde ao significado no texto de origem, em que está associado a práticas discursivas e pende mais a processo que a produto. Ainda, defini-lo como produto pode provocar mal entendido no leitor dos PCN, pois o documento

3 As definições de "produto" e "conjunto" foram extraídas do Dicionário Aurélio da Língua Portuguesa (edição eletrônica) justamente para evidenciar as acepções do senso comum relacionadas aos termos em questão. 
SILVA - A retextualização dos conceitos de letramento...

apresenta a definição de texto também como sendo um produto, conforme veremos mais adiante.

Nos segmentos 4, 5, e 6, que continuam a definição de letramento, temos um fragmento da página 18 do texto de Kleiman (op.cit.), ou seja, uma reordenação tópica (operação V). A sequiência, no texto fonte, é um fragmento em que a autora exemplifica o conceito enquanto objeto de pesquisa num contexto situado específico ${ }^{4}$. Já a retextualização nos PCN usa formas no plural para tornar a definição universal, genérica. As substituições lexicais e sintáticas e algumas eliminações se dão em função da perspectiva bem menos específica. Assim, em 4, uma prática discursiva de determinado grupo social é retextualizado para São práticas discursivas, na forma mais genérica. A referência anafórica (do contexto específico ilustrado) do $5^{\circ}$ fragmento- essa interação oral - desaparece.

A forma retextualizada elimina, também, as referências aos contextos sociais específicos das práticas (operação IV). Isto gera uma redução do conceito em que, para a autora da fonte, a contextualização da prática é marcada, já nos PCN é apagada. As questões contextuais são o ponto central da noção de letramento e eliminá-las pode promover certa proximidade do termo à noção de letramento autônomo, obscurecendo, por conseguinte, a noção de letramento ideológico ${ }^{5}$. O referencial teórico que discute essas duas noções de letramento é o pano de fundo para a conceituação no texto fonte. Entretanto, o contexto comparativo entre letramento autônomo e ideológico é eliminado no texto alvo.

\section{TEXTO E INCOERÊNCIAS}

A definição de texto apresentada nos PCN é uma composição retextualizada do conceito proposto por Fávero e Koch (1988) e Koch e Travaglia (1989), com fragmentos de Geraldi (1995). A primeira parte da definição é uma retextualização do livro "Lingüística Textual: introdução" de Fávero e Koch (op.cit:25) em que as autoras discutem as diferenças conceituais entre texto e discurso, apresentando algumas correntes lingüísticas que diferenciam os dois termos e outras que não os diferenciam (chamaremos este texto fonte de fonte 1).

A segunda parte da definição é retextualizada de "Texto e Coerência" de Koch e Travaglia (op.cit:26) em que os autores discutem a coerência enquanto fator de textualidade

4 Vejamos a seqüência completa do parágrafo de Kleiman: "Se, por outro lado, um pesquisador investiga como adultos e crianças de um grupo social, versus outro grupo social, falam sobre o livro, a fim a de caracterizar essas práticas, e, muitas vezes, correlacioná-las com o sucesso das crianças na escola, então, o letramento significa uma prática discursiva de determinado grupo social, que está relacionada ao papel da escrita para tornar significativa essa interação oral, mas que não envolve, necessariamente, as atividades específicas de ler e escrever. (v. Heath, 1982, 1983; v. também, Rojo, neste volume)".

5 Letramento autônomo e letramento Ideológico são concepções propostas por Street (1984).O primeiro pressupõe uma única maneira de o letramento ser desenvolvido, independentemente das questões contextuais da prática do letramento, ou seja, ele se desenvolve de forma autônoma ou independente do contexto. Já o segundo pressupõe formas plurais de práticas de letramento. O texto de Kleiman (1995) retoma e compara os dois conceitos. 
(chamaremos este segundo texto de fonte 2). O quadro abaixo mostra a conceituação de texto dos PCN confrontada com os textos das fontes. Para melhor visualizar a fonte e a forma retextualizada, segmentamos os textos em enunciados menores, como fizemos com o conceito de letramento. Esclarecemos, entretanto, que na publicação dos PCN, os segmentos que mostraremos a seguir constituem um único parágrafo.

\begin{tabular}{|c|c|c|}
\hline ENUNCIADOS & TEXTO FONTE & PCN - TEXTO ALVO \\
\hline 1 & $\begin{array}{l}\text { O discurso é manifestado, } \\
\text { linguiisticamente, por meio de } \\
\text { textos (em sentido estrito). }\end{array}$ & $\begin{array}{l}\text { O discurso, quando produzido, } \\
\text { manifesta-se lingüisticamente por meio } \\
\text { de textos. }\end{array}$ \\
\hline 2 & $\begin{array}{l}\text { Neste sentido, o texto consiste em } \\
\text { qualquer passagem, falada ou } \\
\text { escrita, que forma um todo } \\
\text { significativo, independente de sua } \\
\text { extensão. }\end{array}$ & $\begin{array}{l}\text { Assim, pode-se afirmar que texto é o } \\
\text { produto da atividade discursiva oral e } \\
\text { escrita que forma um todo significativo } \\
\text { e acabado, qualquer que seja sua } \\
\text { extensão. }\end{array}$ \\
\hline 3 & $\begin{array}{l}\text { Trata-se, pois, de uma unidade de } \\
\text { sentido, de um contínuo } \\
\text { comunicativo contextual que se } \\
\text { caracteriza por }\end{array}$ & \\
\hline 4 & $\begin{array}{l}\text { um conjunto de relações } \\
\text { responsáveis pela tessitura do texto } \\
\text { - os critérios ou padrão de } \\
\text { textualidade, entre os quais } \\
\text { merecem destaque especial a } \\
\text { coesão e a coerência. 9fonte 1) }\end{array}$ & $\begin{array}{l}\text { É um sequiência verbal constituída por } \\
\text { um conjunto de relações que se } \\
\text { estabelecem a partir da coesão (nota } 8 \\
\text { e da coerência. }\end{array}$ \\
\hline 5 & $\begin{array}{l}\text { Textualidade ou textura é o que faz } \\
\text { de uma sequiência linguiística um } \\
\text { texto e naõ um amontoado } \\
\text { aleatório de frases ou palavras. A } \\
\text { seqüência é percebida com um } \\
\text { texto quando aquele que a recebe } \\
\text { é capaz de percebê-la com uma } \\
\text { unidade significativa global. (fonte } \\
\text { 2) }\end{array}$ & $\begin{array}{l}\text { Esse conjunto de relações tem sido } \\
\text { chamado de textualidade. Dessa } \\
\text { forma, um texto só é um texto quando } \\
\text { pode ser compreendido como unidade } \\
\text { significativa global, quando possui } \\
\text { textualidade. Caso contrário, não } \\
\text { passa de um amontoado aleatório de } \\
\text { enunciados. p. } 25 / 26\end{array}$ \\
\hline
\end{tabular}

A definição de texto começa a ser construída, no texto alvo, através da referência ao conceito de discurso, tal como acontece no texto fonte em que as autoras discutem justamente os dois conceitos (ver enunciado 1). Ocorre uma substituição sintática (operação III) que modifica a forma predicativa - é manifestado - no texto fonte para a forma reflexiva manifesta-se - no alvo. Há o acréscimo de uma subordinada reduzida de particípio que, em nosso entender, funciona como contextualizadora, já que a forma retextualizada apaga, neste trecho, a noção de discurso e cria uma outra referência relacionada com a produção verbal. Por isso, ocorre, também, a eliminação do item informacional (operação IV) que exclui a noção de texto a que Fávero e Koch se referiam - em sentido estrito -, já que falavam anteriormente do texto no sentido lato, mais relacionado à noção de discurso. 
SILVA - A retextualização dos conceitos de letramento...

Conseqüentemente, o referencial comparativo que fornece os parâmetros para a interpretação do conceito é apagado, tal como ocorreu com a retextualização da definição de letramento.

No enunciado 2 ocorrem operações de substituição lexical e sintática (operações II e III) - falada ou escrita / oral e escrita; independente de / qualquer que seja. Observa-se que a referência anafórica, que retoma a noção de texto em sentido estrito - Neste sentido - é substituída pelo conectivo Assim (conjunção coordenativa conclusiva).

Mais adiante, aparece um segmento que se diferencia substancialmente da fonte que agrega ao conceito a noção de objeto acabado, noção esta que não está em Fávero e Koch, nem em Koch e Travaglia, mas em Geraldi $(1995: 98,100)$ que escreve:

um texto é o produto de uma atividade discursiva onde alguém diz algo a alguém (p.98. Grifos nossos)

um texto é uma sequiência verbal escrita coerente formando um todo acabado, definitivo e publicado (p.100. Grifos nossos)

Vejamos, no quadro abaixo, a fonte de Fávero e Koch (fonte 1) e a de Geraldi em negrito para melhor visualização:

\begin{tabular}{|l|l|}
\hline \multicolumn{1}{|c|}{ Texto fonte } & \multicolumn{1}{c|}{ Texto alvo } \\
\hline $\begin{array}{l}\text { Neste sentido, o texto consiste em } \\
\text { qualquer passagem, falada ou escrita, } \\
\text { que forma um todo significativo, } \\
\text { independente de sua extensão. } \\
\text { (fonte 1) }\end{array}$ & $\begin{array}{l}\text { Assim, pode-se afirmar que o texto é } \\
\text { o produto da atividade discursiva oral } \\
\text { e escrita que forma um todo } \\
\text { significativo e acabado, qualquer que } \\
\text { seja sua extensão. }\end{array}$ \\
\hline $\begin{array}{l}\text { um texto é o produto de uma } \\
\text { atividade discursiva onde alguém diz } \\
\text { algo a alguém } \\
\text { um texto é uma sequiência verbal } \\
\text { escrita coerente formando um todo } \\
\text { acabado, definitivo e publicado } \\
\text { (Geraldi) }\end{array}$ & \\
\hline
\end{tabular}

Observamos, então, que a definição de texto retextualizada nos PCN incorpora também fragmentos do texto de Geraldi, para quem o texto, na publicação de referência, é concebido como um objeto pronto e acabado. Entretanto, podemos observar que há uma noção importante presente tanto em Geraldi (op.cit) quanto em Koch e Travaglia (op.cit.), que é eliminada na forma retextualizada (operação IV), a saber, a "presença" do outro - o interlocutor - que constitui a noção de texto nas fontes e que é eliminada na conceituação dos PCN. Geraldi (op.cit.98) realça ao definir texto: onde alguém diz algo a alguém e Koch e Travaglia, na fonte, fazem menção ao interlocutor: A seqüência é percebida como um texto quando aquele que a recebe. Em ambos os casos a noção é apagada da forma retextualizada. No enunciado 3, outra importante noção na conceituação de texto é apagada, qual seja: a relação com o contexto que perpassa e caracteriza um texto como tal. 
No enunciado 4 ocorre uma reordenação tópica (operação V) em que a noção de textualidade é colocada em foco e depois relacionada com a coesão e a coerência como constituintes da tessitura. No texto alvo aparece de forma invertida, ou seja, o termo textualidade é apresentado por último. Ainda, as noções de coesão e coerência, na fonte, são colocadas como componentes de um conjunto maior de critérios responsáveis pela textualidade, já no alvo, aparecem como os únicos elementos responsáveis pela textualidade. É interessante observar, ainda no enunciado 4, que há uma nota para definir coesão, entretanto não há qualquer definição de coerência, embora, para Koch e Travaglia, no texto fonte, a coerência seja o fator mais importante para a textualidade, visto que há texto sem coesão, mas não o há sem coerência.

A última parte da retextualização tem como referência a fonte $\mathbf{2}$, em que observamos, na forma retextualizada, uma reordenação tópica (operação V) para organizar a seqüência explicativa do conceito. No texto fonte os autores tinham a textualidade como tópico principal já no alvo o termo passa a denotar uma noção que ajuda a definir texto - o conceito principal. No quadro abaixo, nota-se a inversão tópica no texto alvo. Para melhor comparar as transformações do alvo, sublinhamos as sequiências idênticas e realçamos ora com negrito ora com itálico as inversões:

\begin{tabular}{|c|c|}
\hline Texto fonte & Texto alvo \\
\hline $\begin{array}{l}\text { Textualidade ou textura é o que faz de } \\
\text { uma sequêencia linguística um texto e } \\
\text { não um amontoado aleatório de } \\
\text { frases ou palavras. A sequiência é } \\
\text { percebida como um texto quando } \\
\text { aquele que a recebe é capaz de } \\
\text { percebêla com uma unidade } \\
\text { significativa global. }\end{array}$ & $\begin{array}{l}\text { Dessa forma, um texto só é um texto } \\
\text { quando pode ser compreendido como } \\
\text { unidade significativa global, quando } \\
\text { possui textualidade. Caso contrário, } \\
\text { não passa de um amontoado } \\
\text { aleatório de enunciados. }\end{array}$ \\
\hline
\end{tabular}

Neste segmento, além dos apagamentos já mencionados, ocorre também uma substituição lexical incorreta, do ponto de vista lingüístico - frases ou palavras por enunciados. Para finalizar nossas considerações sobre a retextualização do conceito de texto queremos retomar seu caráter híbrido, que tem como fonte três textos: Fávero e Koch, Koch e Travaglia e Geraldi, ainda que este último de forma bastante breve. A inserção da noção de texto como objeto acabado (vinda de um recorte pontual e descontextualizado de Geraldi) na definição dos PCN torna-se incompatível com a definição de texto proposta pelos autores das demais fontes, para quem o texto em si é um objeto em aberto, dependente de um contexto e de um interlocutor para fazer sentido e constituir-se verdadeiramente um texto.

\section{DISCURSO: O MACRO UNIVERSO DO TEXTO}

O conceito de discurso apresentado nos PCN é uma retextualização do mesmo livro de Fávero e Koch (op.cit.) que serviu de fonte para a conceituação de texto. Como dissemos, as autoras discutiam comparativamente os conceitos de texto e discurso. No material 
SILVA - A retextualização dos conceitos de letramento...

retextualizado, prefere-se definir um conceito e depois o outro, sem relacioná-los, talvez por uma questão didática. No caso de discurso, toma-se um segmento da página 24 das autoras e "enxerta-se" um fragmento da página 25 . No quadro abaixo marcamos com negrito para melhor visualizar a inserção da página 25 na forma retextualizada e em itálico as da página 24.

\begin{tabular}{|c|c|c|}
\hline ENUNCIADOS & TEXTO FONTE & PCN - TEXTO ATNO \\
\hline 1 & $\begin{array}{l}\text { Para os partidarios da } \\
\text { analise do discurso, o } \\
\text { temmo discurso parece } \\
\text { ter o significado mais } \\
\text { amplo que texto, }\end{array}$ & $\begin{array}{l}\text { O discurso possui um } \\
\text { significado amplo: }\end{array}$ \\
\hline 2 & & $\begin{array}{l}\text { refere-se à atividade } \\
\text { commicativa que é } \\
\text { realizada muma } \\
\text { determinada situregăo, }\end{array}$ \\
\hline 3 & $\begin{array}{l}\text { visto emglobas tanto } \\
\text { os enumeiados } \\
\text { pertencentes a uma } \\
\text { mesma fomasad } \\
\text { discumiva como as } \\
\text { suas condisoes de } \\
\text { produsao. (p.2A) }\end{array}$ & 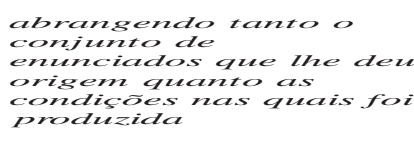 \\
\hline 2 & 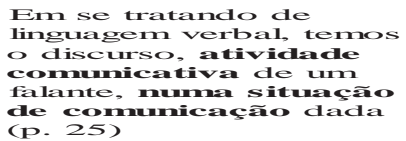 & \\
\hline
\end{tabular}

A referência textual que a fonte faz a uma área de estudo (Análise do Discurso) é eliminada do texto alvo, no enunciado 1 (operação IV). Também a relação entre discurso e texto é suprimida pelo mesmo motivo que já expusemos quando analisamos o conceito de texto (a forma retextualizada não trabalha a definição de texto e discurso comparativamente, como acontece na fonte). No enunciado 2, em decorrência das transformações anteriores, observa-se a eliminação de todo um período (operação IV) - Em se tratando de linguagem verbal, temos o discurso - Há, também, a eliminação de outros itens informacionais importantes como a menção a um falante em - atividade comunicativa de um falante - excluída na forma retextualizada.

O enunciado 3 traz substituições de termos específicos bastante interessantes do ponto de vista da adequação ao público, visto que no texto fonte aparece as noções de formação discursiva e condições de produção que são familiares a lingüistas. Como elas poderiam não ser familiares aos professores alfabetizadores, são substituídas por conjunto de enunciados que the deu origem e condições nas quais foram produzidos, respectivamente. Embora as substituições não signifiquem tudo o que os termos da área significam, há um ajuste aceitável, do ponto de vista teórico.

Na retextualização do conceito de discurso, chamou-nos a atenção, de modo especial, o recorrente apagamento das referências ao interlocutor, ou seja, tal como aconteceu na definição de texto, o interlocutor parece ser relegado a um segundo plano. Entretanto, o apagamento desse elemento constitutivo tanto da noção de texto quanto da de discurso dificulta ao leitor do documento - professor sem formação em lingüística - recuperar 
princípios comunicativos relevantes para o ensino da escrita. O próprio Geraldi (op.cit.) uma das fontes intertextuais dos PCN - realça que "o outro é a medida: é para o outro que se produz o texto" (p. 102). As implicações pedagógicas dessa opção - apagar ou relegar ao segundo plano a presença constitutiva do interlocutor nos conceitos de discurso e texto são importantes e decisivas para a reformulação dos parâmetros de ensino da escrita. Ou seja, sem considerar que toda produção textual destina-se a um (ou vários) interlocutor(es) e que o discurso configura-se na situação comunicativa, esvazia-se qualquer possibilidade de o professor deslocar a produção textual escolar tradicional, como estanque, nas grande maioria das vezes, na relação avaliativa professo/aluno, para a construção de contextos comunicativos favoráveis ao ensino da língua escrita enquanto instrumento de cidadania, conforme preconizam os próprios PCN. Por fim, é curioso observar também que, tal como aconteceu na retextualização do conceito de letramento, os referenciais teóricos e os elementos comparativos (implícitos e explícitos) das fontes são apagados na forma retextualizada.

\section{OS GÊNEROS DO DISCURSO}

Bakhtin (1997) é a fonte da retextualização do conceito de gêneros do discurso nos PCN. O processo de retextualização de gêneros do discurso está mais próximo do que seria um resumo propriamente, já que há uma redução significativa das informações que compõem o texto alvo. Marcamos em negrito os segmentos retextualizados para melhor visualizar o processo de redução textual:

\begin{tabular}{|c|c|c|}
\hline ENUNCIADOS & TEXTO FONTE & PCN - TEXTO ALVO \\
\hline 1 & & $\begin{array}{l}\text { Todo texto se organiza } \\
\text { dentro de um } \\
\text { determinado genero } \\
\text { (nota } 9 \text { ) }\end{array}$ \\
\hline 2 & 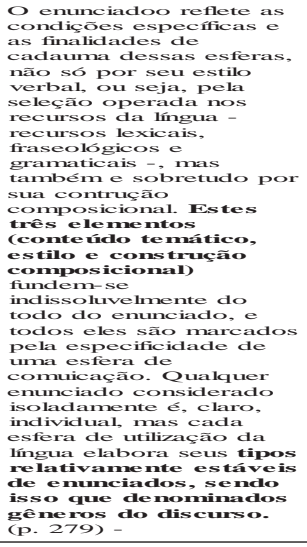 & \multirow[t]{2}{*}{ 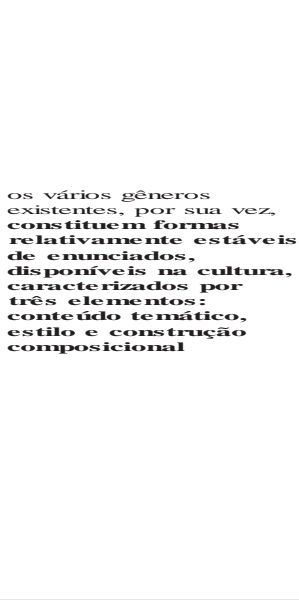 } \\
\hline 3 & $\begin{array}{l}\text { formas típicas de } \\
\text { enunciado, isto } E \text {, aos } \\
\text { generos do discurso }\end{array}$ & \\
\hline
\end{tabular}


SILVA - A retextualização dos conceitos de letramento...

A forma retextualizada mantém apenas a definição pontual do conceito substituindo a palavra tipo por forma (operação II), substituição feita também por Bakhtin em outros momentos do texto fonte, e depois, enumera as categorias que definem o gênero, eliminando as explicações a elas concernentes (operação IV). Observa-se, ainda, que há uma reordenação argumentativa (operação V), já que Bakhtin, no texto fonte, formula o conceito depois de ter discorrido sobre os usos da linguagem a partir das esferas de utilização e da explanação das categorias que caracterizam o gênero (conteúdo temático, estilo e construção composicional). Já a forma retextualizada, ao contrário, primeiramente define gênero do discurso e, depois menciona os elementos caracterizadores do gênero.

A nota número 9, sobre a palavra gênero, traz uma indicação bibliográfica, diferentemente dos demais conceitos analisados ${ }^{6}$. Guiados pela indicação da nota: "O termo "gênero" é utilizado aqui como proposto por Bakhtin e desenvolvido por Bronckart e Scheneuwly" pudemos observar que, de fato, o texto alvo traz traços de Bronckart (1999: 75) que escreve: "todo texto se inscreve, necessariamente, em um conjunto de textos ou em um gênero" enquanto nos PCN (enunciado 1 desmembrado do restante do parágrafo apenas para efeito de análise), temos: "todo texto se organiza dentro de um determinado gênero".

O conceito de gêneros do discurso é fundamental para a proposta dos PCN que defende o ensino da escrita através dos gêneros. Assim, é mister que seu público alvo o compreenda para que seja possível a implantação da proposta de ensino. Mas, como vimos, a definição desse conceito apresenta-se de forma bastante reduzida. Dificilmente o professor das séries iniciais do ensino fundamental (muitos formados apenas em nível de segundo grau) alcançaria a compreensão do conceito através dos PCN.

\section{CONSIDERAÇÕES FINAIS}

Sistematizando, as operações que ocorreram no processo de retextualização dos quatro conceitos, obtivemos o seguinte quadro:

\begin{tabular}{|c|c|c|c|c|}
\hline \multicolumn{2}{|l|}{ OPERAÇÖES } & \multicolumn{3}{|c|}{ CONCEITOS } \\
\hline & Letramento & Texto & Discurso & $\begin{array}{l}\text { Gêneros do } \\
\text { discurso }\end{array}$ \\
\hline $\begin{array}{l}\text { eliminação } \\
\text { vocabular }\end{array}$ & $x$ & $x$ & $x$ & \\
\hline $\begin{array}{l}\text { substituição } \\
\text { lexical }\end{array}$ & $x$ & $x$ & $x$ & $x$ \\
\hline $\begin{array}{l}\text { substituição } \\
\text { sintáctica }\end{array}$ & $x$ & $\mathrm{x}$ & $\mathrm{x}$ & $\mathrm{x}$ \\
\hline 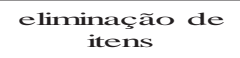 & $x$ & $\mathrm{x}$ & $\mathrm{x}$ & $x$ \\
\hline $\begin{array}{l}\text { reordenação } \\
\text { tópica }\end{array}$ & $x$ & $\mathrm{x}$ & & $x$ \\
\hline
\end{tabular}

6 A nota nos causou certo "estranhamento", já que em nenhum outro momento aparece a referência da fonte dos conceitos retextualizados. 
O quadro nos mostra que os conceitos sofrem quase todas as operações propostas, com exceção de discurso que não tem reordenação tópica e gênero do discurso que não apresenta eliminação vocabular; porém, na retextualização desse último conceito aparecem significativas eliminações de itens informacionais. Queremos realçar, também, que essas operações estão interligadas de modo que a ocorrência de uma pode desencadear a das outras. Uma reordenação tópica, por exemplo, pode exigir substituições lexicais e sintáticas; a eliminação de itens informacionais pode requerer uma reordenação tópica, substituições lexicais e sintáticas etc.

A análise que apresentamos nos revela um aspecto importante do processo de definição de letramento, texto, discurso e gêneros do discurso, qual seja: a ressignificação conceitual que acontece no documento curricular, fruto das próprias operações de retextualização. A conceituação apresentada no documento agrega e tenta ampliar as noções vindas de referenciais teóricos que às vezes se incompatibilizam, conforme observamos na retextualização da definição de texto, quando se adiciona um trecho de Geraldi (1995) na definição proposta por Fávero e Koch (1988).

Também, a omissão de aspectos fundamentais que servem de referências teóricas para a definição do conceito na fonte interfere na ressignificação que ocorre nos PCN. No caso do conceito de letramento, por exemplo, a eliminação das referências contextuais apaga uma característica importante do conceito que é justamente a relação da prática de escrita ao contexto em que se insere. A relação contextual das práticas de escrita é o aspecto que permitiria ao professor diferençar as propostas dos PCN das tradicionais concepções escolares de ensino de língua materna. Outra mudança significativa do ponto de vista da conceituação é a eliminação das referências à interação na definição retextualizada de texto e discurso. Pensamos que a consideração do interlocutor no processo comunicativo poderia ser um dos elementos inovadores dos $\mathrm{PCN}$ que permitiria ao professor redimensionar os conteúdos a serem trabalhados. O resultado desse processo de retextualização é um texto cuja textualidade se dá principalmente através da coerência por intertextualidade, ou seja, é preciso recuperar suas relações intertextuais para que o texto se torne coerente ${ }^{7}$. Entretanto, para o seu público alvo principal - os professores - o texto pode se tornar ilegível, pois, sem o conhecimento das fontes não é possível construir (nem reconstruir) um sentido. Por fim, esperamos que os problemas apontados neste artigo com relação às definições de letramento, texto, discurso e gêneros do discurso nos PCN contribuam para uma reflexão acerca dos processos textuais na divulgação dos conhecimentos produzidos e debatidos na esfera acadêmica ao público não especialista.

\section{REFERÊNCIAS BIBLIOGRÁFICAS}

BAKHTIN, M. (1997). Marxismo e filosofia da linguagem. $8^{\mathrm{a}}$ ed. São Paulo: Hucitec.

FÁVERO, L. L. \& KOCH, I. V. (1988). Lingüística textual: uma introdução. São Paulo: Cortez.

7 Entendemos a coerência como "um princípio de interpretabilidade", conforme proposto por Koch e Travaglia (op.cit.). 
SILVA - A retextualização dos conceitos de letramento...

BRONCKART, J. (1999). Atividade de linguagem, texto e discurso. São Paulo: Educ.

GERALDI, J. W. (1995). Portos de passagem. São Paulo: Martins Fontes.

KLEIMAN, A. B. (1995). Texto e leitor: aspectos cognitivos da leitura. São Paulo: Pontes.

KOCK, I.V. \& TRAVAGLIA, L. C. (1989). Texto e coerência. São Paulo: Cortez.

MEC. (1997). Parâmetros curriculares nacionais: Língua Portuguesa, Ministério da Educação e do Desporto, Secretaria de Educação Fundamental, Brasília.

MARCUSCHI, L. A. (2001). Da fala para a escrita: atividades de retextualização. São Paulo: Cortez.

MATENCIO, M. L. M. (2002). Atividade de (re)textualização em práticas acadêmicas: um estudo sobre o gênero resumo. Revista Scripta, vol. 10, dezembro.

TRAVAGLiA, N. G. (1992). A tradução numa perspectiva textual. Tese de Doutorado - USP: São Paulo. 